\title{
DÜBLIN
}

Technological University Dublin

ARROW@TU Dublin

\section{Broadening Ethics Teaching in Engineering: Beyond the Individualistic Approach}

\author{
Eddie Conlon \\ Technological University Dublin, edward.conlon@tudublin.ie \\ H. Zandvoort \\ Delft University of Technology
}

Follow this and additional works at: https://arrow.tudublin.ie/schmuldistart

Part of the Other Engineering Commons

\section{Recommended Citation \\ Conlon, E. \& Zandvoort, H. (2013). Broadening Ethics Teaching in Engineering: Beyond the Individualistic Approach. Science and Engineering Ethics, 19(4), pp.1589-1594.}

This Article is brought to you for free and open access by the School of Multidisciplinary Technologies at ARROW@TU Dublin. It has been accepted for inclusion in Articles by an authorized administrator of ARROW@TU

Dublin. For more information, please contact arrow.admin@tudublin.ie, aisling.coyne@tudublin.ie, gerard.connolly@tudublin.ie.

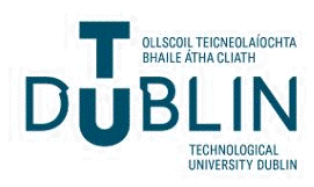




\title{
Broadening Ethics Teaching in Engineering: Beyond the Individualistic Approach
}

\author{
E. Conlon ${ }^{1}$, H. Zandvoort ${ }^{2}$ \\ ${ }^{1}$ Faculty of Engineering, Dublin Institute of Technology, Ireland (Edward.conlon@ dit.ie) \\ ${ }^{2}$ Faculty of Technology Policy and Management, Delft University of Technology, The \\ Netherlands (h.zandvoort@tudelft.nl)
}

\begin{abstract}
There is a widespread approach to the teaching of ethics to engineering students in which the exclusive focus is on engineers as individual agents and the broader context in which they do their work is ignored. Although this approach has frequently been criticised in the literature, it persists on a wide scale, as can be inferred from accounts in the educational literature and from the contents of widely used textbooks in engineering ethics. In this contribution we intend to: (1) Restate why the individualistic approach to the teaching of ethics to engineering students is inadequate in view of preparing them for ethical, professional and social responsibility; (2) Examine the existing literature regarding the possible contribution of Science, Technology and Society (STS) scholarship in addressing the inadequacies of the individualistic approach; and (3) Assess this possible contribution of STS in order to realise desired learning outcomes regarding the preparation of students for ethical and social responsibility.
\end{abstract}

Keywords: engineering education, ethics, social responsibility, STS, sociology

\section{INTRODUCTION}

In a recent article Colby and Sullivan (2008) examine the provision for ethics teaching in undergraduate engineering education in the USA. Key conclusions from their review are that provision for ethics education is inadequate (334), discussion of cases is the most prevalent means of teaching, and that "the broad public purposes of engineering receive little attention in engineering education" (330). They cite research that shows engineering graduates are more likely than others to believe that individuals cannot change society and have lower levels of commitment to social action (335) and suggest that "in developing educational efforts to foster ethical development, it is helpful to think about the goals in broad terms" (335).

Colby and Sullivan have joined a growing list of scholars who have argued for the broadening of ethics education arising from dissatisfaction with what can be called the individualistic approach. This approach focuses narrowly on the ethical commitments of engineers arising from professional codes, uses simplified case studies or scenarios to "train" students to be sensitive to and resolve ethical dilemmas, and sees whistleblowing as a key device for ensuring that engineers can remain true to their codes. According to these scholars this individualistic approach is inadequate to achieve desired learning outcomes such as "an understanding of professional and ethical responsibility", understanding "the impact of engineering solutions in a global and societal context" and having "knowledge of contemporary issues." (ABET accreditation criteria as quoted from Colby and Sullivan 2008: 327). ${ }^{1}$

We concur with the demand for broadening ethics teaching. Our basic question is which kinds of teaching interventions are needed to get engineering students to focus on how they can reshape the social, economic and legal context in which they will work in order to facilitate and support an engineering practice which fulfils "the overall mission of the [engineering] profession as contributing to human welfare" (Colby and Sullivan 2008: 328) and which as a consequence ascribes paramount importance to public safety, sustainability and social justice.

\footnotetext{
${ }^{1}$ At the European level, a canonical formulation of learning outcomes similar to the USA ABET criteria does not exist, although in some countries, such as Ireland, professional bodies with accreditation functions have specified similar learning outcomes to those of ABET. We assume that in Europe desired learning outcomes regarding professional, ethical and social responsibility are not basically different from, or less demanding than those in the USA.
} 


\section{Forthcoming in Science and Engineering Ethics}

Our emphasis is on the need to change the context within which engineers work (Conlon 2008, Donnelly and Boyle 2006, Zandvoort et al. 2000) so that it enables rather than constrains social responsibility. This is in line with what Mitcham (2009) has called a policy turn in engineering ethics. This turn, he claims, is defined by a growing dissatisfaction with individualist ethics and an emerging (if still a minority) consensus that ethics should include "analysis of and on occasion action to transform institutional arrangements and policy directives as they set contexts for the pursuit and practice of engineering" $(46) .^{2}$

Our focus is on the need both for reflexivity (so that existing goals, practices and institutions are not taken for granted) and for a praxis which goes beyond reflexivity towards actual changes of these goals, practices and institutions, as may be needed to protect or enhance (the contributions of engineers to) human welfare. Hence the question we ask is: What attitudes or involvement, which skills, and which knowledge the engineering curricula should instil in their graduates in order to empower them for confronting these needs? Specifically, we will assess in this paper the possible contributions of STS scholarship to this teaching.

We will first characterise the individualistic approach to ethics teaching for students in engineering and discuss its deficiencies (Sections 2 and 3). Next we review the existing literature regarding the possible contribution of STS scholarship in order to correct the deficiencies of the individualistic approach (Sections 4 and 5). In Section 6 we summarise our conclusions regarding what STS scholarship can contribute to engineering education aimed at preparing engineering students for ethical and social responsibility. We also briefly mention further changes in engineering education that remain desirable in view of the mission of the engineering profession as stated above.

\section{THE INDIVIDUALISTIC APPROACH}

Ethics teaching to engineers that we call here the individualistic approach usually develops through the discussion of scenarios (cases) in professional practice, in which an engineer is facing an ethical problem of some sort and in which he/she is required to take a decision. Whether or not these scenarios are fictitious or adapted from an actual case, the following points are characteristic of how they are treated. (Below we will discuss an example. Bucciarelli (2008) discusses other instructive examples.)

1. Focus on the individual actor. There is an almost exclusive focus on the individual engineer from whom an ethical decision is expected. Often, an ethical decision requires a challenge to the interests or goals of the organisation in which the engineer works. Frequently a dilemma arises in which the engineer can either take an ethical decision and face personal sacrifice, or take a less ethical decision while saving his or her personal interests. The personal sacrifice may consist in being fired and/or being criminally prosecuted because of an act of whistle blowing, an act that was nevertheless required for ethical reasons.

2. A framework based on codes of ethics. The scenarios are usually analysed within the framework of the ethical codes of engineers. These codes are assumed to be the principal source of rules that should guide the ethical decisions of the individual engineer. ${ }^{3}$ It is hence implicitly assumed that these rules are sufficiently clear and free of conflicting elements to be applied to particular cases so that they can be applied by an individual agent in the situation at hand.

3. "Neighbour-ethics". If for some reason a justification or a further interpretation or elaboration of the rules provided by the ethical codes is considered necessary, then the individualistic approach preferably takes recourse to traditional moral philosophy for help. This focuses on small scale human interactions ("neighbour-ethics"), while ignoring the ethical problems of multi-actor situations, such as prisoners' dilemma problems, that frequently arise in the context of engineering and technology as well as in organisations (Zandvoort 2000: 196-197; 2005: 26-28). Hence the exclusive focus on individual

\footnotetext{
${ }^{2}$ Mitcham cites some some evidence to support this turn. In addition we would point readers to two special issues of the European Journal of Engineering Education: 25(4) (2000) and 33(2)(2008). See also the outcome of a recent workshop "Teaching ethics and peace to science and engineering students" available at http://www.znf.uni-hamburg.de/brochure.pdf.

${ }^{3}$ For an extensive collection of codes of ethics, both for engineers and for other professionals, see http://ethics.iit.edu/index 1.php/Programs/Codes\%20of\%20Ethics
} 


\section{Forthcoming in Science and Engineering Ethics}

agency stressed in point 1 above is confirmed by a selective tapping from ethical reflection. Selective, because there are other branches of reflection that do address ethical problems of large groups. An example within philosophy is political philosophy. Input from this branch of ethical reflection is usually absent (Winner 1990).

4. Assumption that win-win solutions always exist and can be implemented by individual engineers. In the individualistic approach it is often implicitly or explicitly assumed that it is always possible to resolve an ethical issue in a way that is satisfactory or correct in some objective, non-arbitrary sense; a solution that should hence be selected and implemented by the engineer who is facing the ethical problem. Although this assumption underlies much of the thinking behind the individualistic approach, it is particularly apparent in the literature on how to assess students, e.g. after they have taken a course on engineering ethics. What has been proposed is that students should be assessed on their ability to take ethical decisions in the scenarios discussed above. There are several problems here. For many of these scenarios, it is unclear what an objectively correct or non-arbitrary ethical solution would amount to. At the least, the identification of win-win solutions may require a broader, critical analysis of the organisational, social, legal and political context in which the probem arises. Also, if such solutions exist at all, their implementation will often be beyond the reach of the engineer who is facing the problem. It hence appears to be mistaken to assess students' capability to arrive at correct answers, if those answers are meant to describe solutions that they as engineers could actually implement. We will now take a closer look at this issue.

Shuman et al. (2004) investigated whether students can resolve ethical dilemmas, and whether prior teaching of engineering ethics has an effect on this capacity. The authors were "particularly interested in cases that require what Harris, Prichard and Rabins refer to as "creative middle way solutions," where one must choose among two or more conflicting morally important values." (2005). They distinguished five stages in dealing with an ethical problem, ranging from the recognition of a dilemma to its resolution. The last stage at its highest level of achievement "considers potential risk and/or public safety, and proposes a creative middle ground ("win-win" situation)".

But do win-win solutions exist in all (or most, or many) ethical problems that engineers encounter in their professional practice? And if such solutions exist, can an individual engineer implement them, or would that require changes in the broader context, i.e. at the collective level? Let us consider one of the four scenarios that were actually used by Shuman et al. to assess the ethical capabilities of their students. This is the "Trees" scenario, case 6.5 from Harris, Pritchard and Rabins (2005). It entails the following:
A highway engineer must decide whether or not to cut down old growth trees, against the opposition of a group of environmentalists, in order to reduce the number of traffic accidents. Cutting down part of the trees would make it possible to broaden the road to reduce the accident rate. But environmentalists do not agree, saying that "These accidents are the fault of careless drivers. Cutting down trees to protect drivers from their own carelessness symbolises the destruction of our natural environment for the sake of human 'progress'. It's time to turn things around. Sue the drivers if they don't drive sensibly." ( 183).

Now it is by no means clear what would constitute a win-win solution in this case. Any tree sacrificed for the car drivers might be considered a loss by the environmentalists such that it might not render a "win" solution for them. Should a second road be constructed through less contested area and at the expenditure of the drivers? Should a tax on mileage be introduced to reduce traffic and hence accidents? Such options are probably not within the reach of this particular engineer. Even if they were, that would not automatically solve his problem. For the car drivers and the environmentalists may clash on whether or not there is a right to cut trees. Whether or not such a right exists will determine whether the car drivers or rather the environmentalists will have to pay for the construction of an additional road. But it appears to us that an engineer should or could not decide what the rights of people are, or how conflicting rights, values or interests should be weighted against each other. We also do not think that the codes of ethics referred to in point 2 above contain principles or rules with which such issues could be decided. It is unfortunate that Shuman et al. do not discuss which answers to the ethical problem of the engineer they consider correct, and why. 


\section{Forthcoming in Science and Engineering Ethics}

We conclude from the above that it is unwarranted to assume that win-win solutions to ethical problems encountered by engineers always do exist, or can always be objectively defined, let alone that such solutions are always accessible to the engineers facing the issue.

\section{CRITICISM OF THE INDIVIDUALISTIC APPROACH}

Several authors (Bucciarelli 2008, De George 1981, Herkert 2001, 2004, Kline 2001, Ladd 1980, 1982, Lynch and Kline 2000, Son 2008, Winner 1990, Zandvoort et al. 2000) have criticised the individualistic approach that confirm and add to the points raised above. Thus, it has been remarked that the scenarios used do not faithfully reflect how engineers actually practice engineering. In focusing solely on an individual agent's possible courses of action, these scenarios and exercises not merely oversimplify, but they are also uninformative about the social, the organisational - even the political complexities of practice (Bucciarelli 2008).

It has also been remarked in the literature that the individualistic approach leads to a simplistic view of the responsibilities of the practicing engineer that is too narrow. It means a diversion of attention from the macro-ethical problems of a profession to the micro-ethical problems of an individual (Herkert 2001, 2005). In Herkert's definition, macro-ethical issues involve questions of the collective social responsibility of the engineering profession and societal decisions about technology (2001: 404). Engineers should collectively be involved in debates over public policy issues regarding the development and use of technology. As an example, Herkert (2001) suggests that professional engineering societies should be involved in discussions on product liability reform.

If engineers have a responsibility regarding macro ethical issues, then they should be properly educated in order that they can take up such roles regarding macro ethical issues. As our discussion of the Trees scenario purports to show, macro ethical issues are present in that scenario: it raises fundamentally questions regarding rights and sustainability and the manner in which (collective) decisions should be made about these issues. If, for example, in a succession of situations each time a majority decides, against the will of a minority, to sacrifice $10 \%$ of a natural resource, then after a sufficient number of rounds virtually nothing remains of the resource. Similarly, macro issues arise in the context of almost any other of the scenarios that can be found in popular textbooks on engineering ethics (Harris et al. 2005, Martin and Schinzinger 2004). In addition, many organisational issues must be considered as macro ethical issues as well including questions such as whether the limited liability of corporations is desirable in view of ethics and sustainability, and whether the way in which responsibility between different individuals (including engineers and managers) is actually distributed in hierarchical organisations can be improved. ${ }^{4}$

\section{STS AND ORGANISATIONAL CULTURE}

In light of the deficiencies of the individualistic approach, many have called for alternative approaches to addressing ethical issues and social responsibility in engineering. One significant proposal to which the remainder of this paper is devoted is that the teaching of engineering ethics should be informed by Science, Technology and Society (STS) studies (Bucciarelli 2008, Herkert 2006, Johnson and Wetmore 2004, Kline 2001, Lynch and Kline 2000, Pritchard and Bailie 2006, Swierstra and Jelsma 2006). Two broad approaches to integrating STS into the engineering ethics classroom can be discerned. We will discuss and assess these two approaches in the present and the next section, respectively.

Inspired by Diane Vaughan's (1996) analysis of the Challenger disaster, the first approach focuses on detailed analysis of workplace routines and of the historical and social context in which engineers work (Kline 2001, Lynch and Kline 2000). This work seeks to move away from an agent-centred approach involving unrealistically simplified cases, which focus on amoral calculation of individuals as the cause of accidents, to a consideration of the role of organisational culture and processes. There is a recognition that most engineers operate in an environment where their capacity to make decisions is

\footnotetext{
${ }^{4}$ There is evidence in the literature that the scope of the teaching of ethics in current science education is similarly deficient to what is described here for engineering education. In science education, also, macro-ethical issues are largely being neglected. Zandvoort (2008) provides a brief elucidation and references.
} 


\section{Forthcoming in Science and Engineering Ethics}

constrained by the corporate or organisational culture in which they work (Lynch and Kline 2000: 210) The aim is "to explore how engineers can learn to identify features of their everyday practice that potentially contributes to ethically problematic outcomes before clear-cut ethical dilemmas emerge" (Lynch and Kline 2000: 196). An onus is placed on engineers to exercise imagination to develop strategies to prevent these problematic features from developing in their own practice (202).

While this approach can be welcomed in moving us away from simplified case descriptions lacking their organisational and social context it is not clear where it leads us in relation to changing the structural environment in which engineers operate. Lynch and Kline want to assert the possibility for the imaginative prevention of the "normalisation of deviance" at the workplace. They correctly point to the importance of issues such as contracting and regulation (216) and are critical (201-2) of Vaughan (1996: 415-22) for being sceptical of the possibilities for structural reform. Yet their approach to accident prevention is still focused on the moral responsibility of engineers and less on changing the institutional environment in which they work (Swierstra and Jelsma 2006).

In a critique of Lynch and Kline, Swierstra and Jelsma (2006) argue that STS literature shows that in "modern technology projects" the necessary conditions for individual moral agency are lacking and that the picture painted by Lynch and Kline is far too rosy. They argue, correctly, for a focus on the relationship between individual moral agency on the one hand and on the individual's enabling and constraining environment on the other and call for "an institutional ethics rather than an individual one"(312). In this context it is important to note that Vaughan does not argue against seeking to reform organisations but she believes the impact of such reforms will be limited unless there is change to "control the institutional forces that generate competition and scarcity and the powerful leaders who, in response, establish goals and allocate resources, using and abusing high risk technical systems" (422)

Therefore what happens at the workplace cannot be seen to be independent of wider forces in society.

Lynch and Kline's focus on workplace routines shares similarities with those who have argued that accidents can be better understood as resulting from organisational failure rather than human error or technical failure (Dien at al. 2004). Adopting an approach, not unlike that of STS scholars, it is argued that analysis of accidents must examine historical background and organisational context. What is useful here though is that these scholars generate a "set of predominant and recurrent organisational factors" that demand our attention if we are to analyse (and prevent) accidents. These include the weakness of the organisational safety culture; complex and inappropriate organisation; limited feedback; production pressures and failure of internal and external control (152). This can provide the basis for a programme of reform both at the workplace and in society. We think that Lynch and Kline (2000:199-200) incorrectly dismiss those who argue for the importance of (improving) government regulation or, like Unger (1994), consider the role that engineering societies, codes of ethics, trade unions, lawyers and regulatory agencies can play in bolstering individual and collective responses to moral problems. In order to challenge unethical practices and to promote the public good, legal, organisational, and social reforms are required.

Lynch and Kline are critical of Unger's approach in that, they claim, his focus is on increasing the autonomy of individual engineers in the face of amoral managers. We agree with STS scholars who move away from posing engineering ethical problems as only arising from clashes between engineers and managers to focus more on the practice of engineers. It is the case though that reforms can support engineers in resisting management pressure but also have the potential to change engineering practices. For example, Meiksins and Smith's (1996) comparative study of engineers considers the experiments in work humanization in Sweden. They argue that: "Conditions in Swedish society have imposed on engineers more constraints, and created the conditions for a dual agenda for production efficiency and work humanization" (265) $)^{5}$. In a similar vein Beder (1988: 175-6) shows how laws imposing "previously non-existent constraints" can become "inducement mechanisms" for technological innovations which protect the environment. What can be noted here is the manner in which constraints become enablers for a socially responsible engineering practice.

\footnotetext{
5 They also argue that work humanisation was facilitated because Swedish engineers were closely aligned with manual workers and were engaged in a dialogue with social scientists 'exposing engineers in their training and practice to the benefits of work humanization' (265).
} 


\section{Forthcoming in Science and Engineering Ethics}

Swierstra and Jelsma (2006) argue that a sociologically informed way of studying science and engineering practice can help engineers to recognize the possibilities and obstacles for assuming social responsibility for their work. They believe it is both necessary and possible to influence the institutional environment of engineers so as to enable and stimulate them to behave responsibly. While the construction of such an environment is usually in the hands of other actors engineers can be called on to demand changes in their environment (see also Winner 1990) and can play a role in accomplishing reforms. But they must be properly prepared for that.

\section{MACRO ETHICS}

The second approach to integrating STS and ethics focuses on the need to address macro ethical issues in the teaching of ethics to engineers and demands that STS scholarship adopt an explicitly normative stance. Herkert $(2001,2005,2006)$ has been the foremost proponent of such an approach. He argues that STS concepts are necessary for a complete accounting of the moral problems faced by engineers and to arrive at adequate solutions to these problems (2006: 416). He calls for engagement with "activist orientated" STS to broaden engineering ethics to include discussion of public policy issues of relevance to engineers (415). He does, however argue that a framework for linking micro and macro ethical issues is missing and suggests that a focus on the role of professional bodies may be one approach to developing an integrated framework (2005).

Herkert's approach is useful in distinguishing different "STS subcultures" and in acknowledging that much STS scholarship does not provide guidance for engineers seeking to promote public welfare, sustainability or "otherwise preferable civilisation" (Woodhouse et al. 2002:298, see also Winner 1993). To some extent this results from the micro focus of many STS scholars with an emphasis on descriptions of technological developments and a moral relativism which "provides no solid, systematic standpoint ... from which to criticise or oppose any particular pattern of technical development" (Winner 1993:374) ${ }^{6}$

The following observations can be made regarding this proposed shift to a focus on macro ethical issues.

1. The micro-macro distinction. It is not always clear that macro and micro issues can be easily distinguished. Herkert has, for example, identified the design of safe products as a micro issue. But yet we know that the safety of engineering products and processes is affected by a number of factors such as the regulatory regime and public policy, which includes policy on product liability which Herkert identifies as a macro issue. In the much-used ethics case study centred on the Ford Pinto the absence of Federal safety standards is a key issue (DeGeorge 1981). Indeed De George argues that decisions on safety should not be made solely by engineers and that society should act to prevent engineers "from being squeezed" in the way Ford squeezed them in the Pinto case (10). Rather than trying to neatly demarcate what is or is not a macro or micro issue it might be better to use the sociological distinction between structure and agency (Conlon 2008) as a basis for integrating macro issues into the analysis of engineering practice. A focus on macro issues does not mean that micro issues disappear but rather highlights the need to widen the analysis to look at how the broader environment enables or constrains their capacity, for example, to design safe products. Vaughan $(1996,2008)$ ) has done this effectively by looking at how the disposition to fly with a flawed design was reinforced by institutional and organisational factors. These include the education system, which prepares engineers to "to work in bureaucratic production organisations, where cost, efficiency and schedule are valued and prioritised" (2008: 74)

2. The role of individuals in ethical decision making. It has been argued, most recently by Son (2008), that a shift to an emphasis on macro issues leaves no role for the individual engineer in ethical decision making at a macro level: "being ethical and unethical fades away if one emphasizes a structure that can deal with the macro-level issues" (Son 2008:411). Son characterises the position of those who focus on macro issues as encouraging engineers to think about what is ethical at a micro level while promoting 'policy fixes' at a macro level whereby ethical dilemmas get resolved by changes in the institutional

\footnotetext{
${ }^{6}$ In a reflection on the role of STS post 9/11 Bijker (2003), a leading figure in the STS movement says "The STS agenda has been largely agnostic as to the normative and political issues related to the application of STS insights"
} 


\section{Forthcoming in Science and Engineering Ethics}

structure. These changes are promoted by professional bodies rendering individual action by engineers redundant.

In response we would argue, as shown in section 2 and 3, that ethical dilemmas cannot be easily resolved at the level of the individual engineer. Action is needed at a higher level to help engineers effectively resolve ethical issues in their work. Its not that change at the macro level will lead to a situation where individual decisions are completely determined but rather that "structural change makes certain actions seem necessary while other seem impossible" (Dietz and Burns 1992: 192). The implementation of policy changes will require active decision making by engineers. Further the image of isolated engineers facing ethical dilemmas alone simply does not accord with the practice of engineering. Thus it is not possible to encourage ethical reflection at a micro level without taking macro factors into account.

We do not agree that the proposed shift to a focus on macro issues leaves no role for individual engineers in ethical decision making at this level. Professional bodies decide and act through their members and the process of achieving policy change requires the active engagement of engineers both in their professional bodies and in wider policy making processes. Those who have argued for a macro approach have placed new ethical responsibilities on engineers (Swierstra and Jelsma 2006, Winner 1990, Zandvoort et al. 2000). For example Swierstra and Jelsma have constructed a second order responsibility for engineers "one that urges them to strive actively for the creation of conditions on the engineering work floor that enable the assumption of moral responsibility by individual engineers" (329) while Zandvoort and others have argued that engineers must accept that they must play an active role in helping to reshape the broader context from which ethical problems arise "whenever that may be necessary" (2000: 297). These responsibilities accord with Son's demand that engineers contemplate on their role in making ethical changes in the structure of technological development (2008: 412). The issues that arise here are how this is to be done, what resources engineers, individually and collectively, can draw on in doing so, and how education should empower students to enable them to live up to these wider ethical and social responsibilities. Hence our criticism of the dominant approach to ethics education to engineers is not that it addresses individuals, or holds individuals responsible for what they do or fail to do, but rather that individuals are considered as if he or she was not in a social, organizational, legal, as well as political context; a context, moreover, that may need to be changed if engineering and technology are to contribute to human welfare. The individualistic approach does not provide students with appropriate knowledge and skills for understanding that context and for understanding which changes might be needed and why, and for that reason fails to empower students for responsible decision making and actions.

3. The goals of engineering. Son (2008) has argued that a shift to a macro focus, to which he agrees, should lead to a questioning of the goals of engineering or current forms of technological development (412-3). He says that "..engineers will be obliged to reflect on what kind of society is desirable, to produce sound arguments for their ideas, and to conduct and justify their engineering practices accordingly " $(208,413)$ and he sees a role for the professional societies here. While we agree on the need to question current paths of technological development and the goals and aspirations of engineers our concern is that this should be accompanied by proposals and strategies for change. Otherwise we will end up with a purely aspirational ethics (Bowen 2009) which aspires to the 'Good Society' but offers no map as to how to get there because it does not address the captive nature of the profession. Engineers work within the marketplace and inside large hierarchical organisations (Lynch and Kline 2000: 207) and "possess little power to influence how (their) expertise is ultimately put to use" (Holt 2001: 498). Further diversity of training and the fragmentation of the profession limit its power to direct engineers away from "production-system-induced interest to the human consequences of their technical activities" (Vaughan 1996: 205). Rising the level of analysis to address macro issues and the broader goals of engineering is not enough unless we address the capacity of engineers to practice engineering in a way that promotes safety, sustainability and social justice. For us this means changing the structural context in which they work.

4. The role of professional engineering bodies. Raising the level of analysis in the teaching of ethics to engineering students does not necessarily address the issue of whether professional engineering bodies have the will and capacity to promote real change. While agency generally refers to micro-level individual actors it can also refer to collectivities like groups and organisations such as trade unions and professional bodies (Ritzer 1996). Thus we need to examine the organisational, institutional and cultural resources available to engineers which allow them to intervene in public policy making 


\section{Forthcoming in Science and Engineering Ethics}

processes. This should involve consideration of the values and beliefs of both professional engineering bodies and individual engineers. Thus the role of professional bodies should be subject to critical evaluation and they should be seen as just one actor involved in the development, design and use of technology. We therefore favour a focus on societal decision-making about technology as a focus for macro/micro integration rather than a narrow focus on the role of professional bodies.

The above points can be further developed by exploring Herkert's (2006) suggestion that the issue of sustainability could provide a focus for the integration of engineering ethics and STS and a consequent broadening of the curriculum. While we agree with this general proposition, we want to point to a number of requirements to make this proposal a success.

First, a commitment to a specific path of development will be required which integrates the three pillars of sustainability: the ecological, social and economic. This should lead engineers to question the goals of engineering, the kind of problems they solve and the criteria used to solve them (Johnston et al. 2000). This will mean focusing on meeting vital human needs, promoting both intra and intergenerational equity and public participation in decision making about technology (Mulder 2008).

Second, engineer's understanding of sustainability must be enhanced as many commentators have highlighted the failure of engineers to grapple with the social dimension of sustainability (Herkert 1998, Johnston 1997, Szymkowiak 2003). Research with students suggests there are significant knowledge gaps with respect to the social and economic dimensions of sustainability and environmental legislation, policy and standards (Azapagic et al. 2005, Carew and Mitchel 2002). Colby and Sullivan report that "attention to issues of environmental sustainability in engineering work was... widespread" (2008: 333) but they make no comment on the other dimensions of sustainability.

Third, engineering education must be receptive to the need to change the context in which engineers work to favour sustainable outcomes. Like other macro-ethical problems of technology sustainability "implies cultural, social and economic restructuring" (Donnelly and Boyle 2006: 150). Therefore the engineering profession "must start working to influence the restructuring of current social, political, economic, and institutional paradigms...thus increasing the diversity of acceptable options and our ability to move in more sustainable directions" (153). There is a fundamental tension in capitalist economies in that "... as far as sustainability is concerned, consumerism is a large part of the problem. As far as capitalism is concerned, consumerism is essential" (Dresner 2002: 178) 7 . Thus there are real constraints in the structure of society which must be overcome if we are to move towards a sustainable world.

In light of this it is not surprising that the Declaration of Barcelona adopted in 2004 at the First Engineering Education for Sustainable Development Conference called on educators to prepare engineers to

Participate actively in the discussion and definition of economic, social and technological policies, to help redirect society towards more sustainable development. ${ }^{8}$

This requires a reorientation of engineering education ${ }^{9}$. Donnelly and Boyle (2006: 152-3) argue that there are problems with conventional engineering education in that:

- Traditional techniques of problem solving and design are very much linear, end-of-pipe, and reductionist;

- While students need to be able to recognise the cause of problems and understand the complexity of the interactions that link the problem to environment and society their education does not prepare them to address the complex, interlinked environmental, social, and political concerns that must be understood to provide sustainable engineering solutions;

\footnotetext{
${ }^{7}$ See Woodhouse (2001) for a discussion of engineering and overconsumption.

${ }^{8}$ The full Declaration is available at http://eesd08.tugraz.at/?show=declaration

${ }^{9}$ In relation to sustainability in engineering education special issues of two journals are worthy of mention: European Journal of Engineering Education 33(3); International Journal of Sustainability in Higher Education 5 (3).
} 


\section{Forthcoming in Science and Engineering Ethics}

- Conventional education focuses on problem solving while sustainability requires that engineers became problem framers focusing on the fundamental causes of problems; and

- Developing sustainable approaches to problems will require not only closer integration among engineering disciplines but also knowledge and expertise that is beyond the field of engineering. Johnston (1997) mentions the need for engineering education for sustainability to include, amongst other subjects, social sciences, economics, law and environmental politics.

The above points suggest that we take normative goals or constraints like the ones expressed or implied in the overall mission of engineering serious and prepare students to make and evaluate specific proposals for change aimed at these goals or constraints. A recent review of engineering education by the US National Academy of Engineering (NAE) highlights the increasing role that engineers will need to play in public policy as technology develops and becomes more deeply ingrained in our daily lives (NAE 2004: 37). Given this we must be concerned by the NAE's statement that the "engagement of engineers in public policy issues has been haphazard at best" (38).

We can conclude from the present and the preceding section that the insights of STS scholarship definitely have a role to play in addressing some of the deficiencies of the individualistic approach. Crucially STS seeks to situate the actions of engineers in their historical, organisational and social context, it problematises the capacity of engineers to act by highlighting constraints in their environment and focuses on engineering practice not just the impact of technology on society. By revealing the manner in which technology is socially constructed it can point to possible alternatives (Johnson and Wetmore 2004). But, as Winner says, building such alternatives requires offering "coherent arguments about which ends, principles, and conditions deserve not only our attention but also our commitment" (1993: 374 emphasis added).

\section{CONCLUSIONS}

Our starting point was that the engineering curricula should empower their students for positive contributions to reshaping or reforming the social, economic and legal context of engineering. We say this for two main reasons. First, the goals of the profession as set out in accreditation criteria, codes of ethics and other documents are stated as maximising human welfare and placing paramount importance on public safety, sustainability, and social justice. Achieving such goals requires reform in society and engineers should contribute to the reform process. If the profession has certain ends, then certain conditions are necessary to meet them. Therefore particular inputs into the education of engineers are necessary.

Secondly, the dilemmas faced by individual engineers cannot be resolved by focusing solely on the actions of these individuals as in the dominant individualistic approach to teaching engineering ethics. Effective solutions will require changes to the context in which engineers works. The dominant approach is deficient as it leads to a simplistic view of engineering practice and a diversion of attention from macro-ethical issues of the profession. Our argument is not that there is no role for the individual but rather that to successfully address ethical issues we must focus on the resources available to both individual engineers and their professional bodies in seeking institutional reform that enables social responsibility. There is a requirement for individual engineers to play an active role in reshaping the environment in which they work.

Having examined the individualistic approach we moved to a discussion of the possible contributions of STS scholarship to the educational goal that we identified, and we concluded that insights of STS scholarship can correct at least some of the deficiencies of the individualistic approach, for instance by providing an insight into how technology is socially shaped by dominant interests and insight into social networks, constraining and enabling the practice of engineering. We also saw that STS can be an aid to the integration of macro issues into the analysis of ethical problems in engineering. We hope to have shown that most of the work reviewed in Sections 4 and 5 is helpful in that it moves students away from the idea of engineering as a purely technical activity to consideration of it as a social activity that involves choices which affect people's lives. This type of reflection is a necessary element of any engineering curriculum that aims at preparing students for social responsibility. It will be an aid to the clear articulation of which 'ends, principles and conditions' deserve our commitment, as well as how those ends, principles and conditions can be pursued and realised. 
But we also think that, in addition to the STS tradition, there are other sources of knowledge and reflection that are extremely relevant for the realisation of the teaching goal that we consider here, to empower students for positive contributions to reshaping or reforming the social, economic and legal context of engineering. In order to obtain a better understanding of what should be changed in our basic social institutions and how it can be changed, engagement is also required with political philosophy, critical studies of law, legal systems and organisations, public choice (the theory of collective decision making), economics, as well as the sociology, philosophy and history of technology. Space requirements have prevented detailed treatment of these fields and whether insights from these fields should be taught as part of ethics courses or rather require space elsewhere in the curriculum. What can be concluded even without a detailed analysis of the possible contributions from these other fields is that students need an interlocking set of modules which better prepare them to understand the social, economic and legal context of their work and which gives them the tools to intervene in policy debates with the goal of effecting real and positive change.

\section{References}

Azapagic, A., Perdan, S. and Shallcross, D. (2005). How much do engineering students know about sustainable development? The findings of an international survey and possible implications for the engineering curriculum. European Journal of Engineering Education, 30(1), 1-19.

Beder, S. (1998). The new engineer. Sydney: Macmillan.

Bijker, W.E. (2003). The need for public intellectuals: A space for STS. Science, Technology and Human Values, 28(4).

Bowen, W.R. (2009). Engineering ethics: Outline of an aspirational approach. London: Springer. Bucciarelli, L. L. (2008). Ethics and engineering education. European Journal of Engineering Education, 33(2), $141-149$.

Carew, A.L. and Mitchel, C.A. (2002). Characterising undergraduate engineering students' understanding of sustainability. European Journal of Engineering Education, 27 (4), 349-361. Colby, A. and Sullivan, W.M. (2008). Teaching ethics in undergraduate engineering education, Journal of Engineering Education, 97 (3), 327-338.

Conlon, E. (2008). The new engineer: Between employability and social responsibility. European Journal of Engineering Education, 33(2), 151-159.

De George, R.T. (1981). Ethical responsibilities of engineers in large organizations: The Pinto case. Business \& Professional Ethics Journal, 1(1) 1-14.

Dien, Y., Llory, M. and Montmayeul, R. (2004). Organisational accidents investigation methodology and lessons learned. Journal of Hazardous Materials, 111(1-3), 147-153.

Dietz, T. and Burns, T.R. (1992). Human agency and the evolutionary dynamic of culture. Acta Sociologica, 1992, 35 , 187-200.

Donnelly, R. and Boyle, C. (2006). The Catch-22 of engineering sustainable development. Journal of Environmental Engineering, February 2006, 149-155.

Dresner, S. (2002). The principles of sustainability. London: Earthscan.

Harris, C.E., Pritchard, M.S. and Rabins M.J. (2005). Engineering ethics: Concepts and cases. $3^{\text {rd }}$ rev. ed. New York: Wadsworth.

Hatch, H.J. (1993). Relevant engineering in $21^{\text {st }}$ century. Journal of Professional Issues in Engineering Education and Practice, 119(3), 216-219.

Herkert, J.R. (1998). Sustainable development, engineering and multinational corporations: Ethical and public policy implications. Science and Engineering Ethics, 4 (3), 333-46.

Herkert J. R. (2004). Microethics, macroethics, and professional engineering societies. In National Academy of Engineering (Ed.), Emerging technologies and ethical issues in engineering, (pp. 107-114) Washington, DC: National Academies Press.

Herkert, J.R. (2005). Ways of thinking about and teaching ethical problem solving: Microethics and macroethics in engineering. Science and Engineering Ethics, 11(3), 373-385.

Herket, J.R. (2006). Confession of a shoveler. Bulletin of Science, Technology and Society, 26 (5), 410-418.

Holt, J.E. (2001). The status of engineering in the age of technology, International Journal of Engineering Education, 17 (6), 496-501.

Johnson, D.G. and Wetmore, J.M.(2004). Engineering Ethics: Integrating STS and Practical Ethics, Online: Available: www.sts.virginia.edu/E\&T2004/pdf/Integrating_STS.pdf [Accessed January 16, 2008]. 
Johnston, S. (1997). Sustainability, Engineering and Australian Academe. Society for Philosophy and Technology Quarterly Electronic Journal, 1997, 2 (3/4) [Online] Available:

http://scholar.lib.vt.edu/ejournals/SPT/spt.html.

Johnston, S., McGregor, H. and Taylor, E. (2000). Practice-focused ethics in Australian engineering education. European Journal of Engineering Education, 25 (4), 315-324.

Kline, R. (2001). Using history and sociology to teach engineering ethics. IEEE Technology and Society, 20(4), 13-20.

Ladd, J. (1980). The quest for a code of professional ethics: An intellectual and moral confusion. In R. Chalk, M. S. Frankel, \& S. B. Chafer (Eds.), AAAS Professional Ethics Project: Professional ethics activities in the scientific and engineering societies (pp. 154-159). Washington, DC: American Association for the Advancement of Science.

Ladd, J. (1982). Collective and individual moral responsibility in engineering: some questions. IEEE Technology and Society Magazine, 1 (2): 3-10.

Shuman, L.J., Sindelar, M.F., Besterfield-Sacre, M., Wolfe, H., Pinkus, R.L., Miller, R.L., Olds, B.M., Mitcham, C. (2004). Can our students recognize and resolve ethical dilemmas? Proceedings, ASEE Annual Conference and Exposition. 2004

Lynch, W.T. and Kline, R. (2000). Engineering practice and engineering ethics. Science, Technology and Human Values, 25 (2), 195-225.

Martin, M.W. and Schinzinger,R. (2004). Ethics and engineering. $3^{\text {rd }}$ edition. New York: McGrawHill.

Meiksens, P. and Smith, C. (1996). Engineering Labour, London and New York: Verso.

Mitcham, C. (2009) A historico-ethical perspective on engineering education: from use and convenience to policy engagement, Engineering Studies, 1(1), 35-55.

Mueller, D.C. (2003). Public Choice III. New York: Cambridge University Press.

Mulder, K. (2008). Sustainable Development for Engineers, Sheffield: Greenleaf.

National Academy of Engineering, (2004). The Engineer of 2020, Washington: National Academy of Engineering:.

Pritchard, J. and Baillie, C. (2006). How can engineering education contribute to a sustainable future? European Journal of Engineering Education, 31(5), 555-565

Ritzer,G. (1996). Sociological Theory $4^{\text {th }}$ ed., New York: Mc Graw Hill.

Son, W.C. (2008). Philosophy of technology and micro-ethics in engineering. Science and Engineering Ethics, 14(3), 405-415.

Swierstra, T. and Jelsma, J. (2006). Responsibility without moralism in technoscientific design practice. Science, Technology and Human Values, 31(3), 309-332.

Szymkowiak, S. (2003). Why build a network about introduction of sustainable development into scientific education? European Journal of Engineering Education, 28(2), 179-186.

Unger, S. (1994). Controlling Technology: Ethics and the Responsible Engineer, $2^{\text {nd }}$ ed., New York: John Wiley.

Vaughan, D. (1996). The Challenger Launch Decision. University of Chicago Press. Vaughan, D. (2008). Bourdieu and organisations: the empirical challenge. Theory and Society, 37, 6581.

Vesiland, P.A. and Gunn, A.S (1998). Sustainable development and the ASCE code of ethics. Journal of Professional Issues in Engineering Education and Practice, 124(3), 72-4.

Winner, L. (1990). Engineering ethics and political imagination. In P. Durbin (ed.), Broad and Narrow Interpretations of Philosophy of Technology: Philosophy and Technology 7 (pp. 53-64), Boston: Kluwer.

Winner, L. (1993). Upon opening the black box and finding it empty. Science, Technology and Human Values, 18(3), 362-378.

Woodhouse, E.J. (2001). Curbing overconsumption: Challenge for ethically responsible engineering, IEEE Technology and Society Magazine, Fall 2001, 23-30.

Woodhouse, E. Hess, D., Breyman, S. and Martin,B. (2002). Science studies and activism. Social Studies of Science, 32(2), 297-319.

Zandvoort, H. (2000). Codes of conduct, the law, and technological design and development. in P. Kroes and A. Meijers (Eds.), The Empirical Turn in the Philosophy of Technology.(pp 193-205) Amsterdam etc: Elsevier.

Zandvoort, H. (2005). Good engineers need good laws, European Journal of Engineering Education, 30(1), 21-36.

Zandvoort, H. (2008). Preparing engineers for social responsibility, European Journal of Engineering Education, 33(2), $133-140$ 


\section{Forthcoming in Science and Engineering Ethics}

Zandvoort, H., Van de Poel, I. and Brumsen, M. (2000). Ethics in the engineering curricula: topics, trends and challenges for the future, European Journal of Engineering Education, 25 (4), 291-302. 